\title{
Citric acid production by a novel autochthonous Candida zeylanoides isolate: Optimization of process parameters
}

\section{BILGE SAYIN BÖREKÇi ( $\sim$ bilgesayin@ardahan.edu.tr) \\ Ardahan Üniversitesi https://orcid.org/0000-0002-1898-0428 \\ Mükerrem Kaya}

Ataturk University: Ataturk Universitesi

\section{Yekta Göksungur}

Ege University: Ege Universitesi

\section{Güzin Kaban}

Ataturk University: Ataturk Universitesi

\section{Research Article}

Keywords: autochthonous, organic acid, Candida zeylanoides, optimization, response surface methodology

Posted Date: March 2nd, 2022

DOI: https://doi.org/10.21203/rs.3.rs-1396207/v1

License: (c) (i) This work is licensed under a Creative Commons Attribution 4.0 International License. Read Full License 


\section{Abstract}

In this study, citric acid production by autochthonous Candida zeylanoides 7.12 was investigated and optimized. Response surface methodology (RSM) was used for the analysis of simultaneous effects of the chosen factors and two experiment designs were applied. In the first experimental design, the effects of initial $\mathrm{pH}$ value (5.5-6.5), fermentation time (4-6 days) and initial glucose concentration (125-175 g/L) on citric acid production were investigated. Initial $\mathrm{pH}$ value was adjusted periodically with $\mathrm{NaOH}$. Results of the statistical analysis showed that the model was found to be not applicable sufficiently to the chosen data. A second experimental design was employed by keeping the $\mathrm{pH}$ constant at $\mathrm{pH} 6.5$ using glucose concentration and fermentation time as the process parameters to be optimized. Results of the statistical optimization showed that the fit of the model was good and the lack of fit was not significant at the $5 \%$ $(P<0.05)$. The highest citric acid concentration of $11.36 \mathrm{~g} / \mathrm{L}$ was obtained after 6 days of fermentation with an initial glucose concentration of $125 \mathrm{~g} / \mathrm{L}$. The results indicated that initial glucose concentration and fermentation time were important parameters for citric acid production by $C$. zeylanoides 7.12 and this strain could be used for future studies.

\section{Introduction}

Citric acid is formed in the Krebs cycle when carbohydrates are oxidized to carbon dioxide (Abonama et al. 2014). This organic acid is frequently used in the food, pharmaceutical and cosmetic industries due to its properties such as flavoring and buffer agent, antioxidant and preservative. It has also been used as a detergent co-builder in dishwasher cleaners and cross-linker in the production of biodegradable polymers over the past decade (Rzechonek et al. 2019). CA production was estimated to be around 2 million tons in 2020 (Fickers et al. 2020). Additionally, it has been emphasized that the global CA market will be 3.2 billion dollars by 2023, reaching a Compound Annual Growth Rate (CAGR) of 5.1\% (Behera et al. 2021).

The type and amount of carbon source used, nitrogen and phosphorus limitations, environmental factors such as aeration, trace elements, $\mathrm{pH}$ and temperature, as well as selection and improvement of species are important factors affecting the microbial citric acid production (Yalcin et al. 2010). Additionally, there is a strong interest in finding new strains and enhancing production processes in the last years. It is reported that although Aspergillus niger is mostly used for industrial citric acid production, yeasts have been used by many researchers during the last 40 years for investigating the producer strain capacity (Karasu-Yalcin et al. 2010). On the other hand, isocitric acid can be produced as a by-product in yeast-based citric acid production processes (Cavallo et al. 2017).

In the literature, studies on citric acid production using Candida zeylanoides have been seen to be very limited. However, in some studies, high concentrations of citric acid have been obtained. Hattori and Suzuki (1974) reported that $87 \mathrm{~g} / \mathrm{L}$ citric acid was obtained by C. zeylanoides KY6166 using 10\% (w/v) n-alkane in

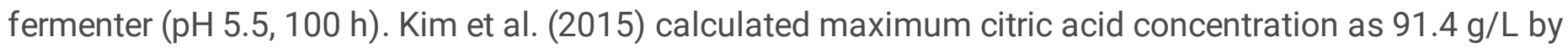
using C. zeylanoides ATCC 20367 with submerged fermentation technique where molasses was used as the substrate. These promising results led to the investigation of $C$. zeylanoides strains as an alternative to $Y$. lipolytica in citric acid production. 
Response surface methodology (RSM) is a statistical technique that helps the design of experiments, create models, search the effect of factors and determine optimum conditions. It is specified that this method is used for optimizing the bioprocess parameters and cultural medium conditions (Göksungur et al. 2011). The object of this study is to determine the citric acid production capacity of $C$. zeylanoides 7.12 strain and to determine the optimal conditions for citric acid production using RSM. Two experimental designs were applied for this purpose. In the first experiment, initial $\mathrm{pH}$ value (5.5-6.5), fermentation time (4-6 days) and initial glucose concentration (125-175 g/L) were used as factors. In the second experimental design glucose concentration (125-175 g/L) and fermentation time (4-6 days) were used as the process parameters to be optimized for citric acid production while keeping the $\mathrm{pH}$ of the medium constant at $\mathrm{pH} 6.5$ using $\mathrm{CaCO}_{3}$. In addition, various yield values of the bioprocess were calculated by determining the concentration of isocitric acid, biomass and consumed glucose during fermentation.

\section{Material And Methods}

\section{Microorganism}

In this study, Candida zeylanoides 7.12 which was previously isolated and genetically identified from pastırma (a Turkish dry-cured meat product) was selected (Kaya et al. 2017) according to its acid production capacity (Sayın Börekçi 2020). Malt Extract Broth (MEB) was used to obtain pre-cultures which were used to inoculate the fermentation media.

\section{Cultivation and fermentation medium}

The pre-cultures were obtained in the MEB medium and then transferred to the modified fermentation medium (MFM). The inoculation ratio was $2 \%(\mathrm{v} / \mathrm{v})$. The MFM medium had the following composition (in grams per liter): glucose, 125,150 or 175 ; yeast extract, $0.5 ; \mathrm{NH}_{4} \mathrm{Cl}, 1.5 ; \mathrm{KH}_{2} \mathrm{PO}_{4}, 1.0 ; \mathrm{MgSO}_{4} .7 \mathrm{H}_{2} \mathrm{O}, 1,5 ; \mathrm{CaCl}_{2}$, $0.15 ; \mathrm{FeCl}_{3} .6 \mathrm{H}_{2} \mathrm{O}, 0.15 ; \mathrm{ZnSO}_{4} .7 \mathrm{H}_{2} \mathrm{O}, 0.02 ; \mathrm{MnSO}_{4} .7 \mathrm{H}_{2} \mathrm{O}, 0.06 ;\left(\mathrm{NH}_{4}\right)_{2} \mathrm{SO}_{4}, 1.0 ; \mathrm{CuSO}_{4}, 0.02$; thiamine, 0.001 (Rane and Sims 1993; Papanikolaou and Aggelis 2002). The citric acid production was carried out in shake flask cultures ( $50 \mathrm{~mL}$ medium $/ 250 \mathrm{~mL}$ flask, $28^{\circ} \mathrm{C}, 180 \mathrm{rpm}$ ).

\section{Chemicals}

Glucose, yeast extract, $\mathrm{KH}_{2} \mathrm{PO}_{4}, \mathrm{CaCl}_{2}, \mathrm{ZnSO}_{4} .7 \mathrm{H}_{2} \mathrm{O}, \mathrm{MnSO}_{4} \cdot 7 \mathrm{H}_{2} \mathrm{O}, \mathrm{CuSO}_{4}$, acetonitrile and malt extract broth were supplied from Merck (Darmstadt, Germany). $\mathrm{MgSO}_{4} \cdot 7 \mathrm{H}_{2} \mathrm{O}, \mathrm{FeCl}_{3} \cdot 6 \mathrm{H}_{2} \mathrm{O},\left(\mathrm{NH}_{4}\right)_{2} \mathrm{SO}_{4}$, thiamine, $\mathrm{NaOH}, \mathrm{CaCO}_{3}, \mathrm{HClO}_{4}, \mathrm{H}_{2} \mathrm{SO}_{4}$ and citric/isocitric acids standards were purchased from Sigma-Aldrich Chemical Company (Steinheim, Germany). $\mathrm{NH}_{4} \mathrm{Cl}$ was purchased from ISOLAB (Istanbul, Turkey).

\section{Analytical methods}

When applying the first experimental design, $\mathrm{pH}$ of MFM was regulated between 5 to 6 with aseptically addition of a $100-400 \mu \mathrm{L}$ volume of $5 \mathrm{~N}$ sodium hydroxide $(\mathrm{NaOH})$ within the periodicity of $18 \mathrm{~h}$ after inoculation and every $24 \mathrm{~h}$ after this time. Additionally, in the second experimental design, the $\mathrm{pH}$ was maintained at 6.5 by $35 \mathrm{~g} / \mathrm{L} \mathrm{CaCO}_{3}$. Cells were removed from the fermentation medium by centrifugation 
(Hettich Universal-320R, Hettich, Frankenberg, Germany) at $9000 \mathrm{rpm}$ for 15 minutes $\left(4^{\circ} \mathrm{C}\right)$. Method by Kamzolova and Morgunov (2017) was modified and used for the determination of citric and isocitric acid concentrations. The supernatant obtained was filtered through a $0.45 \mu \mathrm{m}$ filter and diluted with $8 \% \mathrm{HClO}_{4}$ in an equal volume. Measurements were made in HPLC (Agilent Technologies 1100 Series, Palo Alto, USA) at $210 \mathrm{~nm}$. The column temperature was set at $40^{\circ} \mathrm{C}$ and the flow rate of the mobile phase was $1 \mathrm{~mL} / \mathrm{min} .0 .01$ $\mathrm{M} \mathrm{H}_{2} \mathrm{SO}_{4}$ were used as mobile phase in reverse phase column (Inertsil ODS-3, 4.6×250 mm, GL Sciences Inc., Tokyo, Japan). Citric and isocitric acid standards (Sigma-Aldrich, St. Louis, MO, USA) were used to obtain a calibration curve and to determine quantities. Samples were kept at $-20^{\circ} \mathrm{C}$ until quantification by HPLC.

The supernatant obtained after centrifugation of the fermentation medium was used to determine glucose. Glucose analysis was performed with the supernatant obtained after centrifugation using HPLC (Shimadzu, Kyoto, Japan). Intersil $\mathrm{NH}_{2}(5 \mu \mathrm{m}, 250 \times 4.6 \mathrm{~mm}$ ) (GL Sciences Inc., Tokyo, Japan) column was used and flow rate was $1.3 \mathrm{~mL} / \mathrm{min}$ in the system. Mobile phase was prepared with $75 \%$ acetonitrile ( $25 \%$ ultra-pure water), and column temperature was adjusted to $40^{\circ} \mathrm{C}$ (Anastassiadis and Rehm 2006).

\section{Determination of biomass and $\mathrm{pH}$ level}

Cell growth was evaluated gravimetrically. Biomass was separated by the centrifugation of the fermentation medium and dried to a constant weight at $80^{\circ} \mathrm{C}$ for $24 \mathrm{~h}$. Biomass $(\mathrm{g} / \mathrm{L})$ was calculated as the dry cell weight produced in liters of liquid medium (Anastassiadis and Rehm 2006). When $\mathrm{CaCO}_{3}$ was used to control the pH of the fermentation medium, $6 \mathrm{~N} \mathrm{HCl}$ was used to dissolve residual $\mathrm{CaCO}_{3}$ in the fermentation medium and biomass concentration was determined (Karasu-Yalcin et al. 2010). The pH value of fermentation medium was measured with pH meter (Mettler Toledo lon S220, Switzerland).

\section{Calculation of fermentation parameters}

The following kinetic parameters were calculated in citric acid fermentation using Candida zeylanoides 7.12.

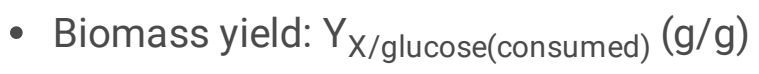

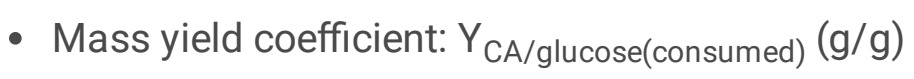

- Citric acid yield on biomass: $\mathrm{Y}_{\mathrm{CA} / \mathrm{X}}(\mathrm{g} / \mathrm{g})$

- Volumetric yield: $Y_{C A / t}(g / L ~ h)$

- Specific product formation rate $\left(\mathrm{q}_{\mathrm{CA}}\right)=\mathrm{CA} /(\mathrm{X} . \mathrm{t})(\mathrm{g} / \mathrm{g} \mathrm{h})$

- Glucose uptake rate=Glucose consumed/(X.t) (g/g h)

- Bioprocess selectivity: $\mathrm{S}_{\mathrm{CA}}(\%)=\left(100 \times \mathrm{CA}_{T}\right) /\left(\mathrm{CA}_{T}+\mathrm{ICA}_{\mathrm{T}}\right)$

\section{Experimental designs}

The statistical analysis of the data was performed using Response Surface Methodology (RSM). Table 1 (A) and $(B)$ shows the levels of factors used in the experimental design. The data of the factors were selected after preliminary experiments. Twenty experiments were conducted using a face central composite statistical design $(a=1)$ for the study of three factors each at three levels (Table 2). Second experimental design 
contained thirteen experiments for the study of two factors each at three levels (Table 5). The levels were -1 , $0,+1$ where 0 corresponded to central point.

The second order response function for three and two quantitative factors are given below. Where $Y$ is the predicted response, $\beta_{0}$ model constant; $X_{1}, X_{2}$ and $X_{3}$ independent variables; $\beta 1, \beta_{2}$ and $\beta_{3}$ are linear coefficients; $\beta_{12}, \beta_{13}$ and $\beta_{23}$ are cross product coefficients and $\beta_{11}, \beta_{22}$ and $\beta_{33}$ are the quadratic coefficients.

\section{Table 1.}

(A)

$$
Y=\beta_{0}+\beta_{1} X_{1}+\beta_{2} X_{2}+\beta_{3} X_{3}+\beta_{11} X_{1}^{2}+\beta_{22} X_{2}^{2}+\beta_{33} X_{3}^{2}+\beta_{12} X_{1} X_{2}+\beta_{13} X_{1} X_{3}+\beta_{23} X_{2} X_{3}
$$

(B)

$$
Y=\beta_{0}+\beta_{1} X_{1}+\beta_{2} X_{2}+\beta_{11} X_{1}^{2}+\beta_{22} X_{2}^{2}+\beta_{12} X_{1} X_{2}
$$

The actual level of the central point of each factor was calculated using the following equation:

Coded value $=($ Actual level $-($ high level + low level $) / 2) /($ high level - low level $) / 2)$

For determining the extent to which the model obtained corresponds to the experimental data, variance analysis (ANOVA) was used. Fischer (F-test) was used for searching the statistical significance (at $95 \%$ confidence level) of linear, quadratic and interaction effects of each factor. It is concluded that the model is fit when the error due to lack of fit is insignificant $(P>0.05)$ and $F$-test for regression was significant $(P<0.05)$. All experiments were performed in duplicate. The statistical analysis of the data was performed using Minitab 17.1.0 software (Minitab Inc., State College, PA, USA).

\section{Results And Discussion}

\section{Results of three-factor experimental design}

Our preliminary experiments showed that initial substrate concentration, initial $\mathrm{pH}$ and fermentation time influenced citric acid production by Candida zeylanoides 7.12 in shake flask cultures. Thus, a face centered design was used to determine the optimum levels of the above mentioned variables leading to maximum citric acid production. The levels of these factors (Table 1A) used in the optimization studies by RSM were determined by preliminary experiments. As shown in Table 2, citric acid concentration values varied between 1.13 and $2.56 \mathrm{~g} / \mathrm{L}$ and isocitric acid which is the byproduct of citric acid fermentation was produced almost more than citric acid in all fermentation trials. Glucose in the fermentation medium was consumed by $C$. zeylanoides 7.12.

\section{Table 2.}


$\mathrm{R}^{2}$ is described as the ratio of the explained variation to the total variation and is a measure of the degree of fit (Neşeli et al. 2011). The small value of $R^{2}$ indicates that the less relevant the dependent variables in the model have in explaining the behavior variation. It is indicated that if $\mathrm{R}^{2}$ approaches unity, the better the response model fits the actual data (Fu et al. 2007). In this situation, it is specified that the less the difference between the predicted and actual values (Chiang 2008). Additionally, if $R^{2}$ values are higher than 0.8 , it means that regression models explained the reaction well ( $\mathrm{Sin}$ et al. 2006). The correlation coefficient $\left(R^{2}\right)$ value, which shows the fit between the experimental data and the predicted data, was determined to be $66.60 \%\left(R^{2}{ }_{a d j}\right)$. In these conditions, it was decided that model was not fit and could not adequately explain the variation observed in citric acid production with the designed levels of the factors.

\section{Table 3.}

\section{Results of two-factor experimental design}

A second experimental design was performed to investigate the effect of initial substrate concentration and fermentation time on citric acid production when $\mathrm{pH}$ was kept constant at $\mathrm{pH} 6.5$ using $\mathrm{CaCO}_{3}$. $\mathrm{CaCO}_{3}$ for $\mathrm{pH}$ adjustment was used before sterilization of the fermentation medium at a concentration of $35 \mathrm{~g} / \mathrm{L}$. The effect of two previously mentioned variables, each at 3 levels and their interactions on citric acid production by Candida zeylanoides 7.12 were determined by carrying out 13 experiments given by the model (Table 4). As seen in Table 5, the highest citric acid concentration $(11.36 \mathrm{~g} / \mathrm{L})$ was obtained at the $6^{\text {th }}$ day of fermentation with an initial glucose concentration of $125 \mathrm{~g} / \mathrm{L}$ glucose. The lowest citric acid concentration $(5.63 \mathrm{~g} / \mathrm{L})$ was achieved in the fermentation medium with an initial glucose concentration of $175 \mathrm{~g} / \mathrm{L}$ after 4 days of fermentation. At all points in experimental design, glucose was consumed by the autochthonous strain. Biomass concentration varied between 12.18-18.50 g/L.

\section{Table 4.}

Yalcin et al. (2009) showed that 44.39 and $37.66 \mathrm{~g} / \mathrm{L}$ citric acid were achieved in $280 \mathrm{~h}$ by autochthonous $Y$. lipolytica 57, when 150 and $100 \mathrm{~g} / \mathrm{L}$ glucose were used in the fermentation medium, respectively. Çelik et al. (2014) obtained $12 \mathrm{~g} / \mathrm{L}$ of citric acid and $1.41 \mathrm{~g} / \mathrm{L}$ of isocitric acid at the end of $216 \mathrm{~h}$ when $100 \mathrm{~g} / \mathrm{L}$ glucose was used as the fermentation medium with $Y$. lipolytica TEMYL 3. Although this concentration is very close to the maximum concentration $(11.36 \mathrm{~g} / \mathrm{L})$ obtained in our study, there is a significant difference between the concentration of isocitric acid and fermentation time. In the present study, it is thought that the citric acid concentration will increase by extending the fermentation time. Arslan et al. (2016) investigated the effects of different $\mathrm{pH}$ values on citric acid production by $\mathrm{Y}$. lipolytica B9 strain and they obtained the maximum citric acid concentration at pH $5.5(8.6 \mathrm{~g} / \mathrm{L})$.

As seen in Table 5 was, the highest CA/ICA ratio (568.1), $\mathrm{Y}_{\mathrm{X} / \mathrm{glucose}}(0.15), \mathrm{Y}_{\mathrm{CA} / \text { glucose }}(0.9), \mathrm{Y}_{\mathrm{CA} / \mathrm{X}}(0.61)$ and selectivity of bioprocess $(99.82 \%)$ were found at the $2^{\text {nd }}$ day of fermentation when the initial glucose concentration was $125 \mathrm{~g} / \mathrm{L}$. The formation of very low concentrations of isocitric acid resulted in high values of CA/ICA and high selectivity of the bioprocess. The highest $\mathrm{Y}_{\mathrm{CA} / \mathrm{t}} \mathrm{y}$ yield (0.09) was achieved at run number 1 and the highest $\mathrm{q}_{\mathrm{CA}}$ yield $(0.005)$ was obtained at runs 1,5 and 6 . The highest and lowest glucose uptake 
rates were calculated as 0.15 and 0.05 at runs 6 and 2, respectively. Kamzolova and Morgunov (2017) reported that $C$. zeylanoides VKM Y-6, VKM Y-14 and VKM Y-2324 produced 3.81, 3.60 and $2.90 \mathrm{~g} / \mathrm{L}$ citric acid, $1.61,1.91$ and $1.91 \mathrm{~g} / \mathrm{L}$ isocitric acid respectively. On the other side, they also determined that the $\mathrm{g}_{\mathrm{CA} / \mathrm{gcell}}$ yields were $1.03,1.13$ and 0.97 respectively. Compared to the results in the literature, higher citric acid and selectivity were obtained in this study while the yields on the cell were lower (due to high biomass formation).

\section{Table 5.}

Analysis of variance (ANOVA) for the citric acid concentration is presented in Table 6. $R^{2}$ was 0.994 indicating that the model as fitted explained $99.4 \%$ of the variability in citric acid concentration. Also, the lack of fit $(0.270)$ was not significant at a level of $5 \%(P<0.05)$. These results show that the model chosen can satisfactorily explain the effects of initial pH level, fermentation time and initial glucose concentration on citric acid production by C. zeylanoides 7.12.

\section{Table 6.}

The following model was fitted for citric acid concentration:

\section{$Y=34,25-0,3038 X_{1}-0,576 X_{2}+0,001135 X_{1}^{2}+0,4895 X_{2}^{2}-0,02240 X_{1} X_{2}$ Equation 1}

$Y$ : Citric acid concentration, $X_{1}$ : Initial glucose concentration, $X_{2}$ : Fermentation time

Estimated regression coefficients for citric acid concentration is shown in Table 7. Initial glucose concentration had negative linear effect, and fermentation time had a positive linear effect on citric acid production $(P<0.05)$ (Table 7). This results shows that with increasing glucose concentration, the citric acid concentration will decrease, and when the fermentation time progresses, the citric acid concentration will increase. The fermentation time had the highest impact on citric acid production as given by the highest linear coefficient (0.9583). Initial glucose concentration and fermentation time showed significant positive quadratic effect on citric acid production $(P<0.05)$. The negative interaction between substrate concentration and fermentation time was significant as shown by low $P$ values $(P<0.05)$ for interactive terms. This indicated that citric acid concentration increased with the increase in these parameters; they reached a maximum and then decreased at high levels of the given factors.

\section{Table 7.}

In Figure 1, when one of the factors was kept constant in the center, the effects of other factor levels on the concentration of citric acid were shown with contour and surface graph.

The fitting of the experimental data to Eq. 1 allowed the determination of the levels of initial sugar concentration ( $125 \mathrm{~g} / \mathrm{L}$ ) and fermentation time (6 days) giving a maximum citric acid concentration of 11.36 $\mathrm{g} / \mathrm{L}$. The above data optimizes citric acid production by $C$. zeylanoides 7.12 in shake flasks. The final fermentation (validation trial) was performed with the optimized levels. Maximum citric acid concentration 
$(11.95 \mathrm{~g} / \mathrm{L})$ which was close to the value given by the model was obtained at the 6 days of fermentation from a glucose concentration of $125 \mathrm{~g} / \mathrm{L}$.

\section{Figure 1.}

\section{Conclusion}

The increasing demand for citric acid has increased the interest in the development of existing processes. The creation and optimization of new processes is important to make production processes more cost effective and efficient. This study investigates citric acid production by autochthonous Candida zeylanoides 7.12. RSM was used to determine the effects of initial subsatrate concentration and fermentation time on citric acid production using cells of $C$. zeylanoides 7.12. The model generated in this study by RSM satisfied all the necessary arguments for its use in optimization of citric acid fermentation. By fitting the experimental data to a second-order polynomial equation, optimum levels of the variables were determined. Using optimum levels of fermentation parameters, a maximum citric acid concentration of $11.95 \mathrm{~g} / \mathrm{L}$ was obtained. According to validation trial, it was shown that the data obtained from the predicted model fitted well with the laboratory results. The kinetic parameters of citric acid formation by $C$. zeylanoides 7.12 in shake flasks were also calculated and given in the manuscript. It is considered that this study contributed to the discovery of new strains and to the use of autochthonous isolates in citric acid production.

\section{Abbreviations}




\begin{tabular}{|c|c|}
\hline Adj MS & Adjusted mean square \\
\hline Adj SS & Adjusted sum of square \\
\hline CA & Citric acid \\
\hline CAIICA & Citric acid/isocitric acid ratio \\
\hline DF & Degrees of freedom \\
\hline$G_{R}$ & Residual glucose concentration \\
\hline ICA & Isocitric acid \\
\hline $\mathrm{pH}_{0}$ & Initial $\mathrm{pH}$ value \\
\hline $\mathrm{pH}_{\mathrm{F}}$ & Final $\mathrm{pH}$ value after fermentation \\
\hline $\mathrm{q}_{\mathrm{CA}}$ & Specific citric acid production rate \\
\hline $\mathrm{s}_{\mathrm{CA}}$ & Selectivity of the bioprocess \\
\hline SE coefficient & Standard error of the coefficient \\
\hline Seq SS & Sequential sum of squares \\
\hline $\mathrm{t}$ & Fermentation time \\
\hline $\mathbf{x}$ & Biomass \\
\hline $\mathrm{Y}_{\mathrm{CA} / \text { glucose }}$ & Mass yield coefficient \\
\hline$Y_{\mathrm{CA} / \mathrm{t}}$ & Volumetric yield \\
\hline $\mathrm{Y}_{\mathrm{CA} / \mathrm{X}}$ & Citric acid yield on biomass \\
\hline$Y_{X / \text { glucose }}$ & Biomass yield \\
\hline
\end{tabular}

\section{Declarations}

\section{Acknowledgement}

This project was supported by TUBITAK (Turkish Scientific and Technical Research Council), Project Number: 1190739. The authors would also like to thank Atatürk University Eastern Anatolia High Technology Application and Research Center (DAYTAM) Directorate.

Conflict of interest. None declared.

\section{References}


1. Abonama OM, Mahrous EH, Hamza HA (2014) Production of citric acid by Candida lipolytica under fermentation conditions using a plackett-burman design. Am J Food Nutr 2(3):43-48

2. Anastassiadis S, Rehm HJ (2006) Citric acid production from glucose by yeast Candida oleophila ATCC 20177 under batch, continuous and repeated batch cultivation.Electron J Biotechnol9(1)

3. Arslan NP, Aydogan MN, Taskin M (2016) Citric acid production from partly deproteinized whey under non-sterile culture conditions using immobilized cells of lactose-positive and cold-adapted Yarrowia lipolytica B9. J Biotechnol 231:32-39

4. Behera BC, Mishra R, Mohapatra S (2021) Microbial citric acid: Production, properties, application, and future perspectives. Food Front 2(1):62-76

5. Cavallo E, Charreau H, Cerrutti P, Foresti ML (2017) Yarrowia lipolytica: a model yeast for citric acid production. FEMS Yeast Res 17(8):fox084

6. Celik G, Uçar F, Akpinar O, Corbaci C (2014) Production of citric and isocitric acid by Yarrowia lipolytica strains grown on different carbon sources.Turkish J Biochem39(3)

7. Chiang KT (2008) Modeling and analysis of the effects of machining parameters on the performance characteristics in the EDM process of $\mathrm{Al}_{2} \mathrm{O}_{3}+\mathrm{TiC}$ mixed ceramic. Int $J$ Adv Manuf Syst 37(5):523-533

8. Fickers P, Cheng H, Sze Ki Lin C (2020) Sugar alcohols and organic acids synthesis in Yarrowia lipolytica: where are we? Microorganisms 8(4):574

9. Fu J, Zhao Y, Wu Q (2007) Optimising photoelectrocatalytic oxidation of fulvic acid using response surface methodology. J Hazard Mater 144(1-2):499-505

10. Göksungur Y, Uzunoğulları P, Dağbağı S (2011) Optimization of pullulan production from hydrolysed potato starch waste by response surface methodology. Carbohydr Polym 83(3):1330-1337

11. Hattori K, Suzuki T (1974) Large scale production of erythritol and its conversion to D-mannitol production by n-alkane-grown Candida zeylanoides. Agric Biol Chem 38(6):1203-1208

12. Kamzolova SV, Morgunov IG (2017) Metabolic peculiarities of the citric acid overproduction from glucose in yeasts Yarrowia lipolytica. Bioresour Technol 243:433-440

13. Karasu-Yalcin S, Tijen Bozdemir M, Yesim Ozbas Z (2010) Effects of different fermentation conditions on growth and citric acid production kinetics of two Yarrowia lipolytica strains. Chem Biochem Eng Q 24(3):347-360

14. Kaya M, Çinar K, Fettahoğlu K, Kaban G, September (2017) Clermont-Ferrand, France

15. Kim KH, Lee HY, Lee CY (2015) Pretreatment of sugarcane molasses and citric acid production by Candida zeylanoides. Microbiol Biotechnol Lett 43(2):164-168

16. Neşeli S, Yaldız S, Türkeş E (2011) Optimization of tool geometry parameters for turning operations based on the response surface methodology. Measurement 44(3):580-587

17. Papanikolaou S, Aggelis G (2002) Lipid production by Yarrowia lipolytica growing on industrial glycerol in a single-stage continuous culture. Bioresour Technol 82(1):43-49

18. Rane KD, Sims KA (1993) Production of citric acid by Candida lipolytica Y1095: Effect of glucose concentration on yield and productivity. Enzyme Microb Technol 15(8):646-651 
19. Rzechonek DA, Dobrowolski A, Rymowicz W, Mirończuk AM (2019) Aseptic production of citric and isocitric acid from crude glycerol by genetically modified Yarrowia lipolytica. Bioresour Technol 271:340-344

20. Sayın Börekçi B (2020) Determination of citric acid production capacity of autochthonous Candida zeylanoides strains. DoctoralDissertation,AtatürkUniversity,Erzurum

21. Sin HN, Yusof S, Hamid NSA, Rahman RA (2006) Optimization of enzymatic clarification of sapodilla juice using response surface methodology. J Food Eng 73(4):313-319

22. Yalcin SK, Bozdemir MT, Ozbas ZY (2009) A comparative study on citric acid production kinetics of two Yarrowia lipolytica strains in two different media. Indian J Biotechnol 8:408-417

23. Yalcin SK, Bozdemir MT, Ozbas ZY (2010) Citric acid production by yeasts: fermentation conditions, process optimization and strain improvement. Curr Res Technol Educ Top Appl Microbiol Microb Biotechnol 9:1374-1382

\section{Tables}

Table 8 is not available with this version.

Table 8. Estimated regression coefficients for citric acid concentration based on the second experimental design

Table 1. Levels of factors used in experimental designs (A) Three-factor experimental design, (B) Two-factor experimental design

\section{(A)}

\begin{tabular}{ccccc} 
& & \multicolumn{3}{c}{ Levels } \\
\hline Factor & Independent variables & $-\mathbf{l}$ & $\mathbf{0}$ & $+\mathbf{l}$ \\
$\boldsymbol{X}_{\mathbf{1}}$ & Initial $\mathrm{pH}$ value & 5.5 & 6.0 & 6.5 \\
$\boldsymbol{X}_{\mathbf{2}}$ & Fermentation time (days) & 4 & 5 & 6 \\
$\boldsymbol{X}_{\mathbf{3}}$ & Glucose concentration $(\mathrm{g} / \mathrm{L})$ & 125 & 150 & 175
\end{tabular}

(B)

\begin{tabular}{ccccc} 
& & \multicolumn{3}{c}{ Levels } \\
\hline Factor & Independent variables & $-\mathbf{l}$ & $\mathbf{0}$ & $+\mathbf{l}$ \\
$\boldsymbol{X}_{\mathbf{1}}$ & Glucose concentration $(\mathrm{g} / \mathrm{L})$ & 125 & 150 & 175 \\
$\boldsymbol{X}_{\mathbf{2}}$ & Fermentation time (days) & 4 & 5 & 6
\end{tabular}

Table 2. Citric acid, isocitric acid, biomass, residual glucose concentrations and final pH levels of citric acid fermentation by Candida zeylanoides 7.12 in three-factor experimental design 


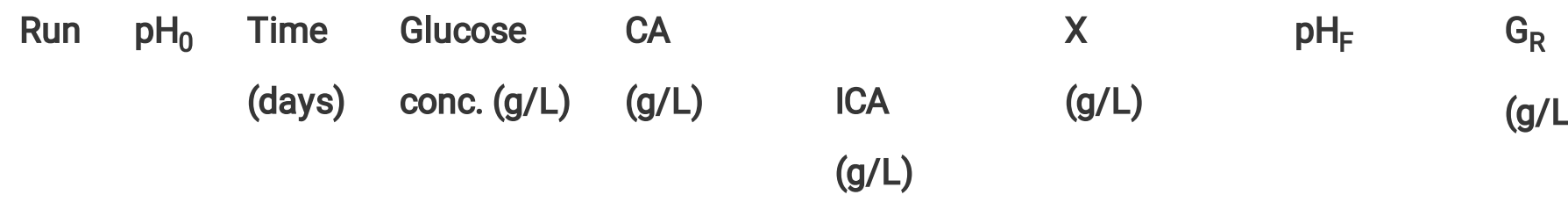

\begin{tabular}{|c|c|c|c|c|c|c|c|c|}
\hline 1 & 6.0 & 5 & 150 & $1.65 \pm 0.84$ & $8.64 \pm 0.23$ & $6.57 \pm 0.34$ & $5.37 \pm 0.06$ & $2.20 \pm 1.03$ \\
\hline 2 & 6.5 & 6 & 175 & $2.25 \pm 0.43$ & $6.40 \pm 1.28$ & $7.37 \pm 0.37$ & $5.31 \pm 0.39$ & $1.36 \pm 1.32$ \\
\hline 3 & 6.5 & 5 & 150 & $1.68 \pm 0.66$ & $6.64 \pm 0.48$ & $6.12 \pm 0.17$ & $5.45 \pm 0.05$ & $1.81 \pm 0.63$ \\
\hline 4 & 5.5 & 5 & 150 & $1.71 \pm 0.59$ & $2.66 \pm 0.47$ & $5.85 \pm 0.16$ & $5.52 \pm 0.31$ & $2.41 \pm 2.41$ \\
\hline 5 & 6.0 & 5 & 150 & $2.17 \pm 0.05$ & $6.97 \pm 1.63$ & $6.64 \pm 0.15$ & $5.45 \pm 0.16$ & $1.96 \pm 0.59$ \\
\hline 6 & 6.0 & 5 & 150 & $2.05 \pm 0.05$ & $7.38 \pm 0.18$ & $6.79 \pm 0.29$ & $5.30 \pm 0.08$ & $0.64 \pm 0.74$ \\
\hline 7 & 5.5 & 6 & 125 & $2.31 \pm 0.57$ & $4.21 \pm 1.58$ & $9.06 \pm 0.89$ & $7.87 \pm 0.30$ & $1.23 \pm 1.73$ \\
\hline 8 & 6.0 & 5 & 150 & $2.11 \pm 0.32$ & $6.96 \pm 0.01$ & $5.99 \pm 0.04$ & $5.68 \pm 0.42$ & $2.27 \pm 0.66$ \\
\hline 9 & 5.5 & 4 & 125 & $2.42 \pm 0.09$ & $8.86 \pm 5.72$ & $7.11 \pm 1.29$ & $5.37 \pm 0.13$ & $2.05 \pm 0.13$ \\
\hline 10 & 6.0 & 4 & 150 & $2.16 \pm 0.14$ & $8.73 \pm 2.52$ & $6.35 \pm 0.01$ & $5.26 \pm 0.13$ & $2.05 \pm 1.06$ \\
\hline 11 & 6.5 & 4 & 125 & $2.56 \pm 0.29$ & $10.01 \pm 0.2$ & $7.43 \pm 0.47$ & $5.37 \pm 0.33$ & $1.85 \pm 0.11$ \\
\hline 12 & 5.5 & 4 & 175 & $1.13 \pm 0.13$ & $3.91 \pm 0.44$ & $5.23 \pm 0.23$ & $5.19 \pm 0.00$ & $1.84 \pm 0.33$ \\
\hline 13 & 5.5 & 6 & 175 & $1.47 \pm 0.50$ & $6.99 \pm 0.15$ & $7.32 \pm 0.08$ & $5.39 \pm 0.08$ & $1.59 \pm 0.12$ \\
\hline 14 & 6.0 & 5 & 175 & $1.71 \pm 1.35$ & $13.48 \pm 4.94$ & $7.04 \pm 0.76$ & $5.45 \pm 0.01$ & $1.47 \pm 0.13$ \\
\hline 15 & 6.5 & 6 & 125 & $2.07 \pm 0.22$ & $2.96 \pm 0.19$ & $10.08 \pm 0.55$ & $8.12 \pm 0.06$ & $1.29 \pm 1.82$ \\
\hline 16 & 6.0 & 5 & 150 & $2.28 \pm 0.12$ & $7.25 \pm 1.00$ & $6.55 \pm 0.18$ & $5.40 \pm 0.01$ & $2.85 \pm 2.61$ \\
\hline 17 & 6.5 & 4 & 175 & $2.18 \pm 0.25$ & $9.82 \pm 0.83$ & $6.97 \pm 0.04$ & $5.19 \pm 0.3$ & $0.87 \pm 0.30$ \\
\hline 18 & 6.0 & 6 & 150 & $1.91 \pm 0.04$ & $6.76 \pm 0.77$ & $6.53 \pm 0.19$ & $5.43 \pm 0.18$ & $0.21 \pm 0.30$ \\
\hline 19 & 6.0 & 5 & 150 & $2.12 \pm 0.00$ & $6.80 \pm 0.52$ & $6.69 \pm 0.77$ & $5.39 \pm 0.02$ & $0.81 \pm 0.70$ \\
\hline 20 & 6.0 & 5 & 125 & $2.32 \pm 0.17$ & $8.81 \pm 0.01$ & $7.52 \pm 0.25$ & $5.77 \pm 0.21$ & $1.19 \pm 1.25$ \\
\hline
\end{tabular}

CA: Citric acid; ICA: Isocitric acid; GR: Residual glucose concentration; $\mathrm{pH}_{\mathrm{F}}$ : Final pH value after fermentation; $\mathrm{X}$ : Biomass

Table 3. ANOVA for citric acid concentration of $C$. zeylanoides 7.12 based on the first experimental design 


\begin{tabular}{lllllll} 
Source & DF & Seq SS & Adj SS & Adj MS & F & P \\
\hline Regression & 9 & 1.96647 & 1.96647 & 0.21850 & 5.21 & 0.008 \\
\hline Linear & 3 & 1.17272 & 1.17272 & 0.39091 & 9.32 & 0.003 \\
\hline Square & 3 & 0.14781 & 0.14781 & 0.04927 & 1.17 & 0.368 \\
\hline Interaction & 3 & 0.64594 & 0.64594 & 0.21531 & 5.13 & 0.021 \\
\hline Residual error & 10 & 0.41935 & 0.41935 & 0.04194 & & \\
\hline Lack of fit & 5 & 0.18462 & 0.18462 & 0.03692 & 0.79 & 0.601 \\
\hline Pure error & 5 & 0.23473 & 0.23473 & 0.04695 & & \\
\hline Total & 19 & 2.38582 & & & &
\end{tabular}

Adj MS: Adjusted mean square; Adj SS: Adjusted sum of square; DF: Degrees of freedom; Seq SS: Sequential sums of squares

Table 4. Citric acid, isocitric acid, biomass and glucose consumption concentrations of citric acid fermentation by Candida zeylanoides 7.12 in two factor experimental design

\begin{tabular}{lllllll} 
Run & $\begin{array}{l}\text { Glucose } \\
\text { conc. }(\mathbf{g} / \mathbf{L})\end{array}$ & $\begin{array}{l}\text { Time } \\
\text { (days) }\end{array}$ & $\begin{array}{l}\text { CA } \\
(\mathbf{g} / \mathbf{L})\end{array}$ & $\mathbf{I C A}(\mathbf{g} / \mathbf{L})$ & $\mathbf{X}$ & $\mathbf{G}_{\mathbf{R}}$ \\
\hline $\mathbf{1}$ & 125 & 4 & $8.36 \pm 0.63$ & $0.20 \pm 0.21$ & $17.02 \pm 0.10$ & $0.00 \pm 0.00$ \\
\hline $\mathbf{2}$ & 125 & 6 & $11.36 \pm 0.21$ & $0.02 \pm 0.01$ & $18.50 \pm 0.42$ & $0.00 \pm 0.00$ \\
\hline $\mathbf{3}$ & 175 & 5 & $5.77 \pm 0.27$ & $0.94 \pm 0.10$ & $12.22 \pm 0.37$ & $0.00 \pm 0.00$ \\
\hline $\mathbf{4}$ & 150 & 5 & $6.80 \pm 0.31$ & $0.32 \pm 0.02$ & $14.79 \pm 0.72$ & $0.05 \pm 0.06$ \\
\hline $\mathbf{5}$ & 150 & 4 & $6.35 \pm 0.61$ & $0.52 \pm 0.08$ & $14.47 \pm 2.26$ & $0.04 \pm 0.02$ \\
\hline $\mathbf{6}$ & 175 & 4 & $5.63 \pm 0.21$ & $0.94 \pm 0.00$ & $12.18 \pm 0.32$ & $0.13 \pm 0.01$ \\
\hline $\mathbf{7}$ & 125 & 5 & $9.36 \pm 0.04$ & $0.03 \pm 0.02$ & $17.85 \pm 1.17$ & $0.00 \pm 0.00$ \\
\hline $\mathbf{8}$ & 150 & 5 & $6.64 \pm 0.57$ & $0.48 \pm 0.52$ & $13.97 \pm 0.95$ & $0.11 \pm 0.06$ \\
\hline $\mathbf{9}$ & 150 & 5 & $6.82 \pm 0.03$ & $0.53 \pm 0.18$ & $15.30 \pm 0.13$ & $0.17 \pm 0.08$ \\
\hline $\mathbf{1 0}$ & 175 & 6 & $6.39 \pm 0.08$ & $0.76 \pm 0.01$ & $11.87 \pm 0.26$ & $0.17 \pm 0.23$ \\
\hline $\mathbf{1 1}$ & 150 & 5 & $6.62 \pm 0.11$ & $0.33 \pm 0.04$ & $15.54 \pm 0.54$ & $0.23 \pm 0.01$ \\
\hline $\mathbf{1 2}$ & 150 & 6 & $8.34 \pm 1.14$ & $0.07 \pm 0.03$ & $15.03 \pm 0.95$ & $0.44 \pm 0.51$ \\
\hline $\mathbf{1 3}$ & 150 & 5 & $6.84 \pm 0.59$ & $0.32 \pm 0.04$ & $15.08 \pm 0.52$ & $0.10 \pm 0.13$
\end{tabular}

CA: Citric acid; ICA: Isocitric acid; GR: Residual glucose concentration; X: Biomass

Table 5. Yields of citric acid production by Candida zeylanoides 7.12 


\begin{tabular}{lllllllll} 
Run & CA/ICA & $Y_{X / g l u c o s e}$ & $Y_{\text {CA/glucose }}$ & $Y_{\text {CA/X }}$ & $Y_{\text {CA/t }}$ & $\mathbf{q}_{C A}$ & Glucose uptake rate & $S_{\text {CA }}(\%)$ \\
\hline $\mathbf{1}$ & $41.8: 1$ & 0.14 & 0.07 & 0.49 & 0.09 & 0.005 & 0.08 & 97.66 \\
\hline $\mathbf{2}$ & $568.0: 1$ & 0.15 & 0.09 & 0.61 & 0.08 & 0.004 & 0.05 & 99.82 \\
\hline $\mathbf{3}$ & $6.1: 1$ & 0.07 & 0.03 & 0.47 & 0.05 & 0.004 & 0.12 & 85.99 \\
\hline $\mathbf{4}$ & $21.3: 1$ & 0.10 & 0.05 & 0.46 & 0.06 & 0.004 & 0.08 & 95.51 \\
\hline $\mathbf{5}$ & $12.2: 1$ & 0.10 & 0.04 & 0.44 & 0.07 & 0.005 & 0.11 & 92.43 \\
\hline $\mathbf{6}$ & $\mathbf{6 . 0 : 1}$ & 0.07 & 0.03 & 0.46 & 0.06 & 0.005 & 0.15 & 85.69 \\
\hline $\mathbf{7}$ & $312.0: 1$ & 0.14 & 0.07 & 0.52 & 0.08 & 0.004 & 0.06 & 99.68 \\
\hline $\mathbf{8}$ & $13.8: 1$ & 0.09 & 0.04 & 0.48 & 0.06 & 0.004 & 0.09 & 93.26 \\
\hline $\mathbf{9}$ & $12.9: 1$ & 0.10 & 0.05 & 0.45 & 0.06 & 0.004 & 0.08 & 92.79 \\
\hline $\mathbf{1 0}$ & $\mathbf{8 . 4 : 1}$ & 0.07 & 0.04 & 0.54 & 0.04 & 0.004 & 0.10 & 89.37 \\
\hline $\mathbf{1 1}$ & $\mathbf{2 0 . 1 : 1}$ & 0.10 & 0.04 & 0.43 & 0.06 & 0.004 & 0.08 & 95.25 \\
\hline $\mathbf{1 2}$ & $119: 1$ & 0.10 & 0.06 & 0.55 & 0.06 & 0.004 & 0.07 & 99.17 \\
\hline $\mathbf{1 3}$ & $\mathbf{2 1 . 4 : 1}$ & 0.10 & 0.05 & 0.45 & 0.06 & 0.004 & 0.08 & 95.53
\end{tabular}

$\mathrm{CA} / \mathrm{ICA}$ : Citric acid/isocitric acid ratio; $\mathrm{q}_{\mathrm{CA}}$ : Specific citric acid production rate; $\mathrm{S}_{\mathrm{CA}}$ : Selectivity of the bioprocess; $\mathrm{Y}_{\mathrm{CA} / \text { glucose: }}$ : Mass yield coefficient; $\mathrm{Y}_{\mathrm{CA} / \mathrm{t}}:$ Volumetric yield; $\mathrm{Y}_{\mathrm{CA} / \mathrm{X}}$ : Citric acid yield on biomass; $Y_{X / g l u c o s e}:$ Biomass yield

Table 6. ANOVA for citric acid concentration of $C$. zeylanoides 7.12 based on the second experimental design

\begin{tabular}{lllllll} 
Source & DF & Seq SS & Adj SS & Adj MS & F & P \\
\hline Regression & 5 & 31.264 & 31.264 & 6.2528 & 406.45 & $<0.001$ \\
\hline Linear & 2 & 26.754 & 26.754 & 13.3772 & 869.56 & $<0.001$ \\
\hline Square & 2 & 3.2552 & 3.2552 & 1.6276 & 105.80 & $<0.001$ \\
\hline Interaction & 1 & 1.2544 & 1.2544 & 1.2544 & 81.54 & $<0.001$ \\
\hline Residual error & 7 & 0.1077 & 0.1077 & 0.0154 & & \\
\hline Lack of fit & 3 & 0.0634 & 0.0634 & 0.0211 & 1.91 & 0.270 \\
\hline Pure error & 4 & 0.0443 & 0.0443 & 0.0111 & & \\
\hline Total & 12 & 31.3717 & & & &
\end{tabular}

Adj MS: Adjusted mean square; Adj SS: Adjusted sum of square; DF: Degrees of freedom; Seq SS: Sequential sums of squares 
Table 7. Estimated regression coefficients for citric acid concentration based on the second experimental design

\begin{tabular}{lllll} 
Term & Coefficient & SE coefficient & T & P \\
\hline Constant & 6.7759 & 0.515 & 131.57 & 0.000 \\
\hline Glucose conc. & -1.8817 & 0.0506 & -37.16 & 0.000 \\
\hline Time & 0.9583 & 0.0506 & 18.93 & 0.000 \\
\hline Glucose conc. x Glucose conc. & 0.7095 & 0.0746 & 9.51 & 0.000 \\
\hline Time x Time & 0.4895 & 0.0746 & 6.56 & 0.000 \\
\hline Glucose conc. $x$ Time & -0.5600 & 0.0620 & -9.03 & 0.000
\end{tabular}

SE coefficient: Standard error of the coefficient

Figures 

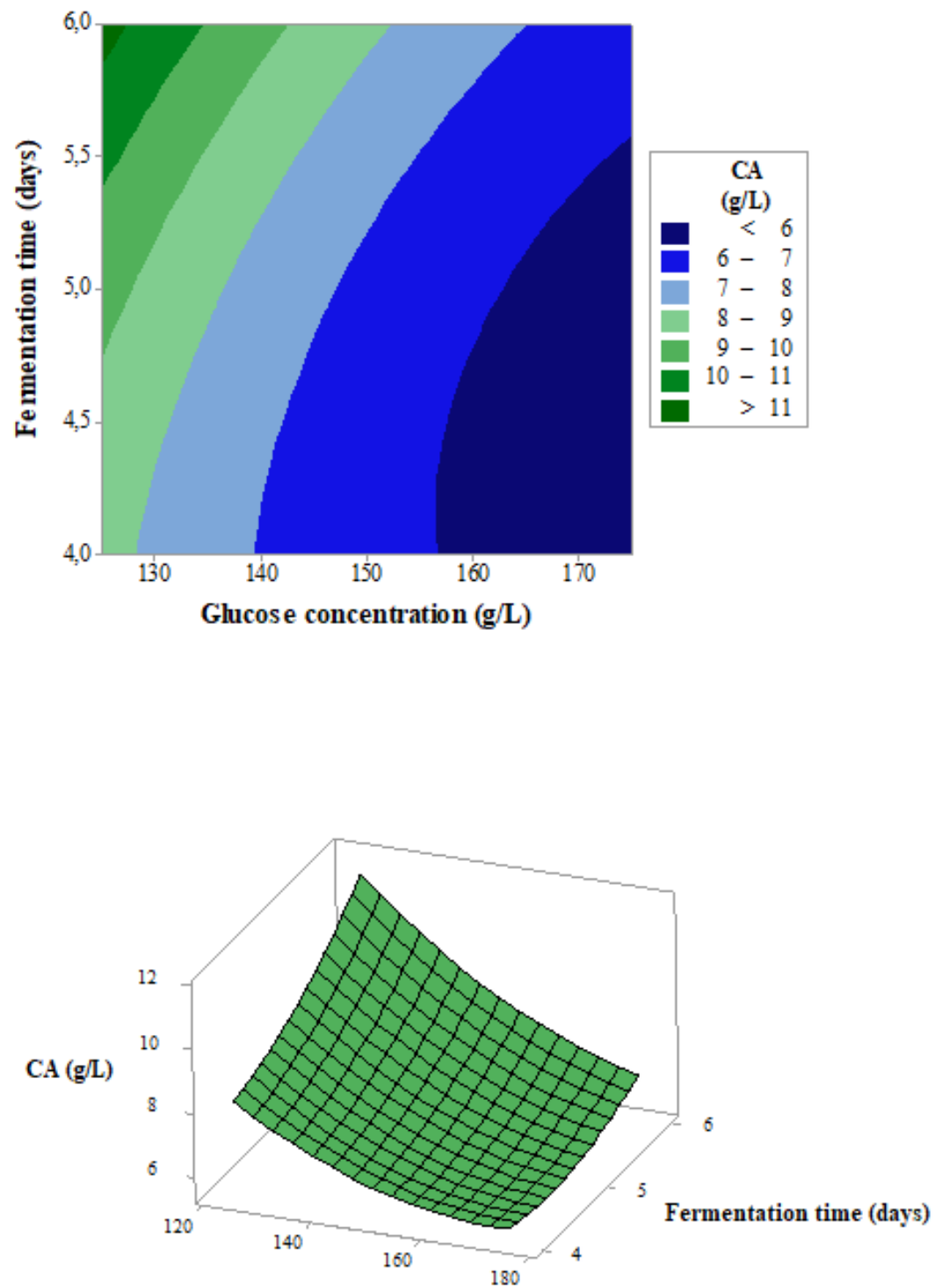

Glucose concentration $(\mathrm{g} / \mathrm{L})$

\section{Figure 1}

Contour and surface plots for citric acid concentration at varying initial glucose concentration and fermentation time 